\title{
Pregnancy: Protection of the Hyperactive Brain, or a Risk Factor?
}

\author{
Zakaria I. Nanobashvili, Irine G. Bilanishvili, Arkadi G. Surmava, Nata G. Bukia, \\ Marine P. Butskrikidze, Lamara I. Machavariani, Nino T. Samsieshvili, \\ Maia G. Barbaqadze, Irma G. Khachidze, Nadejda A. Khizanishvili \\ Department of Neurophysiology, Ivane Beritashvili Center of Experimental Biomedicine, Tbilisi, Georgia \\ Email: besarionsaba@yahoo.com
}

Received 30 May 2014; revised 12 July 2014; accepted 25 July 2014

Copyright (C) 2014 by authors and Scientific Research Publishing Inc. This work is licensed under the Creative Commons Attribution International License (CC BY). http://creativecommons.org/licenses/by/4.0/ c) (i) Open Access

\begin{abstract}
The main objective of the study was to determine the effect of gestation and postgestation periods on development and course of seizure activity. The data obtained in the study showed that i) there is a reduction of both EEG and behavioral seizures during gestation in the presence of hippocampal epileptogenic locus (kindling model); ii) suppression of audiogenic seizures occurs in gestation, and development of audiogenic kindling and decrease of seizure reactions occur in the pseudogestation state. It is assumed that in gestation period the intensification of the possible endogenous inhibitory mechanisms follows the course of seizure activity.
\end{abstract}

\section{Keywords}

\section{Gestation, Kindling, Audiogenic Seizures, Rats}

\section{Introduction}

Elucidation of the relationship between pregnancy and epilepsy remains one of the actual problems in neurology [1]-[3]. The mechanisms responsible for hormonal modulation of seizure susceptibility, however, are still poorly understood as it has been shown that women can be either seizure-sensitive or seizure-nonsensitive to sexual steroids [4] [5] depending on the phase of menstrual or estrous cycle in epileptic subjects. Researchers paid relevant attention to the importance of steroidal hormones in epilepsy after Gowers W.R. [6] had described the intensification of seizure reactions in women during menstruation. These observations led to a convention that reduction of seizures in a midluteal phase should be associated secondarily with progesterone secretion, whereas seizures' intensification during menstruation is due to a reduction of progesterone level. It has been also demonstrated that administration of estrogen appears to exacerbate epilepsy, whereas progesterone and some of its five 
reduced metabolites have potent inhibitory effects on epileptic seizures [7]-[9]. However some studies showed that progesterone had no effect on kindling in the adult animal [10].

Numerous studies over the last few decades have identified sex- and cycle-dependent differences in seizure susceptibility in rodents. These studies used various methods to induce seizures, including kindling, electroshock, and chemoconvulsant drug administration [11]-[13]. However, these studies failed to provide a clear picture of the relationship between ovarian hormone levels and seizure susceptibility.

It is worth to mention that, when such clinical observations are made, one has to bear in mind epilepsy type, localization of epileptic locus, etc. Quite often such approach lacks due attention. Besides, the study of interdependence between epileptic fits and pregnancy in humans is complicated from the ethic point of view and also because of anti-epileptic therapy. Therefore, one of the ways to investigate this problem is using laboratory animal models, in which interactions between seizures and the gestation can be studied under more controlled conditions than it is possible in human population.

Kindling is the animal model for human temporal lobe epilepsy. During kindling initial subconvulsive stimulation of limbic structures causes short-lasting electroencephalographic (EEG) paroxysmal discharges, without any behavioral seizure manifestations. In response to such stimulation the augmentation of EEG seizure discharges and their propagation in different brain structures develop, followed by generalization of seizure activity and behavioral manifestation [14].

Genetically epilepsy-prone rats are used as an animal model of epilepsy. In this context the animals, which develop clonic-tonic behavioral seizure reactions to a strong sound stimulus, deserve special attention. The neuronal substrate of audiogenic seizure activity is localized in the nuclei of inferior colliculi [15] [16].

There were two main objectives of the study: first, the clarify the effect of rat's gestation and postgestation periods on already formed epileptogenic focus (model of kindling); second, the effect of gestation and postgestation periods on the development and course of audiogenic seizure activity.

\section{Methods}

Rats with body mass of 200 - 250 g were housed under the standard laboratory conditions with a " $12 \mathrm{~h}$ light - 12 h dark" cycle, constant temperature of $22^{\circ} \mathrm{C} \pm 2^{\circ} \mathrm{C}$, and water and food ad libitum. Animal care and handling throughout the experimental procedures were in accordance with the European Community Council Directive of 24 November 1986 (86/609/EEC). Use of the animals in the experiments, animal care, and post-experimental euthanasia were performed in a strict adherence to the officially adopted rules for animal use and care in biological laboratories [17].

Subject to the specificity of the study, experiments were carried out on female rats kept in isolation from males. Wistar $(n=16)$ and genetically audiogenic seizure-determined rats $(n=16)$ of Krushinski-Molodkina (KM) line were used in the study [18].

The course of seizure activity is known to be altered with the day/night circadian rhythm [19]. Taking this into account, the observation on the course of seizure reactions was performed at the same time of a day (at 11.00 12.00).

Model of kindling. In female rats forty-fold electric stimulation (50 Hz, duration 5 sec, current 400 - $450 \mu \mathrm{A}$, at $5 \mathrm{~min}$ intervals) was applied to the ventral hippocampus ( $-4.8 \mathrm{~mm}$ from bregma caudally; $5.2 \mathrm{~mm}$ from the midline laterally; $6.5 \mathrm{~mm}$ from dura mater ventrally) during one day. At kindling, initial subconvulsive stimulation of the hippocampus evoked short-lasting (3 - 5 sec) EEG paroxysmal discharges, with no behavioral manifestations of seizures. The enhancement of EEG seizure discharges, propagation in various brain structures followed by generalization of seizures and behavioral manifestation occurred in response to every consecutive subconvulsive stimulation. The kindling state suggests formation of epileptogenic locus in the animal's brain. At $24 \mathrm{~h}, 2$ and 4 weeks after the procedure was completed 5 test stimulation was applied to the same structure with 5 min intervals. In the process of kindling the EEG and behavioral parameters of seizures were assessed. For this reason the Racine [20] scale: 0—nomal behavior, arrest; 1—shaking movement, facial clonus; 2-nodding of the head, backward deviation; 3-forepaw clonus; 4-standing on hindpaws, forepaw clonus; 5—fall on a side or on the back.

Audiogenic seizures. Genetically seizure-determined KM rats were placed in an audiogenic stimulation chamber. The chamber represented $60 \times 60 \times 60 \mathrm{~cm}$ plexiglass box, in the upper part of which a standard wall bell was attached. The animal was in the chamber and an audiogenic stimulus was delivered to it. A high pitch 
sound stimulus was presented to rats (bell intensity $110 \mathrm{~dB}$, time $60 \mathrm{sec}$ ), in response to which they developed seizure reactions. Motor components of seizure activity were estimated by a slightly modified Jobe [21] scale: 0-fear reaction; 1-facial muscle clonus; 2-head tremble, jaw myoclonus; 3-wild run, forepaw myoclonus; 4-myoclonus of fore- and hindpaws, fall on a side; 5-clonus of the fourpaws, skeletal muscle rigidity, ataxia, asphyxia. The mentioned KM line rats fall into two sublines: a) animals, which, in response to a high pitch sound stimulus, develop fear reaction and facial muscle clonus-conventionally referred to as the first subline and b) animals developing fear and wild run to sound stimulus followed by clonic-tonic behavioral seizuresconventionally refered to as the second subline.

Audiogenic kindling. To obtain audiogenic kindling we used the KM line first subline rats- the animals, which, in response to sound stimulus, developed only fear reaction and facial muscle myoclonus. It is remarkable that they developed seizure activity evidenced in behavioral clonic-tonic responses after reiterative sound stimulus. It was shown that triggering of various brain structures (limbic and diencephalic structures, neocortex) occurs in parallel with such multiple repetition of sound stimulus. Involvement of various brain structures in seizure activity in response to sound stimuli is called "audiogenic kindling"-similar to the phenomenon described by Goddard [14] on reiterative stimulation of the limbic structures. In our experiments, in order to obtain audiogenic kindling, sound stimulus was delivered twice in the morning (10.00) and in the afternoon (16.00).

Ovariectomy. Ovariectomy surgery was performed in ether-anesthetized rats by bilateral excision of ovaries. Experiments were conducted 12 - 14 days after ovariectomy.

Ascertaining of rat's gestation. The animal's gestation was established examining ovarial smear (after administration of saline solution) by means of microscopic observation of spermatozoids and later by palpation.

Pseudogestation model. To receiving pseudogestation state in ovariectomized rats, progesterone (60 mg/kg) was injected intraperitoneally. Later on, proceeding from the goal of experiment, "knock-out" of allopregnanolone was performed by the intraperitoneal injection of finasteride, a blocker of progesterone metabolism (60 - 70 $\mathrm{mg} / \mathrm{kg})$.

\section{Data Analysis}

The results obtained were statistically processed by the methods of descriptive statistics and paired 2-tailed t-test $(\alpha<0.05)$. Data were considered valid with $p<0.05$.

\section{Results}

\subsection{Kindling. Changes in Seizure Activity Prior to and after Gestation}

In animal models for human temporal lobe epilepsy we studied the variation of seizure activity (stimulation of the ventral hippocampus) before and after gestation. At 24 h, 2 and 4 weeks after the end of kindling in response to test stimulation of the hippocampus both EEG and behavioral seizures were enhanced (Figure 1).

To assess the effect of gestation period, hippocampal test stimulation was applied at the end of 2nd and 3rd week of gestation. At the end of the 2nd week of gestation the duration of EEG seizure activity showed a considerable reduction from $88 \pm 5.6 \mathrm{sec}$ to $51 \pm 6.6 \mathrm{sec}(p<0.01)$. At the same time, behavioral seizures also were found to show significant attenuation from $3.7 \pm 0.2$ grade to $1.96 \pm 0.4$ grade $(p<0.01)$. At the end of the 3rd week of gestation seizure activity had a similar tendency to attenuation. Namely, compared to hippocampal test stimulation, the duration of EEG seizures reduced from $88.2 \pm 5.6 \mathrm{sec}$ to $34.2 \pm 7.2 \mathrm{sec}(p<0.01)$, while behavioral seizures were suppressed from $3.72 \pm 0.2$ to $2.28 \pm 0.3(p<0.05)$. The recovery of both the EEG and behavioral seizure activity occurred on the $10^{\text {th }}-14^{\text {th }}$ day after the end of gestation.

\subsection{The Effect of Gestation on the Development/Course of Audiogenic Seizure Activity}

As being established, the audiogenic seizure activity represents a kind of generalized convulsive epilepsy. Such seizure activity develops due to activation of brain stem structures. Despite the fact that the primary generation of epileptic activity occurs in the inferior colliculi, the subcortical structures as well as the structures of anterior brain compartment are likely to be implicated in this process.

The conducted experiments revealed that during gestation there was an increase in wild run latency duration, whereas wild run length shows no considerable changes. In particular, we found a considerable decrease in duration of clonic-tonic seizure activity following wild run until its complete disappearance (Figure 2). 


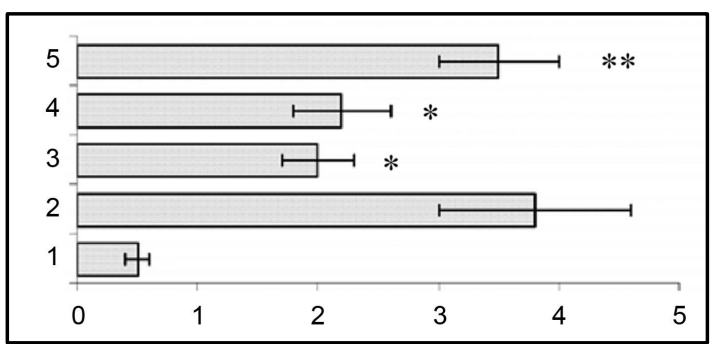

(a)

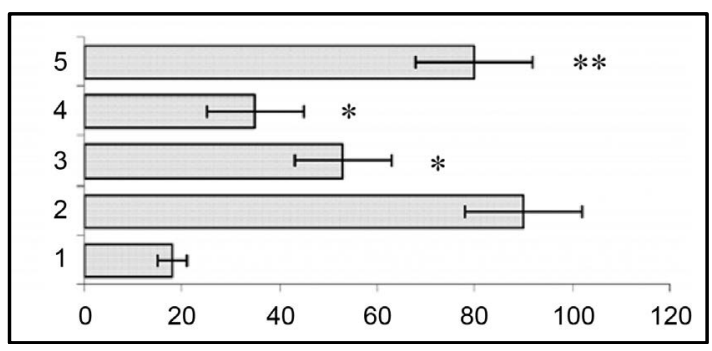

(b)

Figure 1. Changes in behavioral (a) and EEG (b) seizure reactions prior to and after gestation. Ordinate: 1-seizure activity levels in response to the first 5 stimuli during a kindling procedure; 2 - seizure reaction in pregestation period; 3-at the end of gestation 2nd week; 4-at the end of gestation 3rd week; 5-at the end of postgeatation 2nd week. Abscissae: (a) behavioral seizure's levels; (b) duration of EEG seizures in sec. ${ }^{*} p<0.05$ compared to the seizure activity in pregestation period, ${ }^{* *} p<0.05$ compared to the seizure activity at the 2 nd and 3rd postgestation weeks.

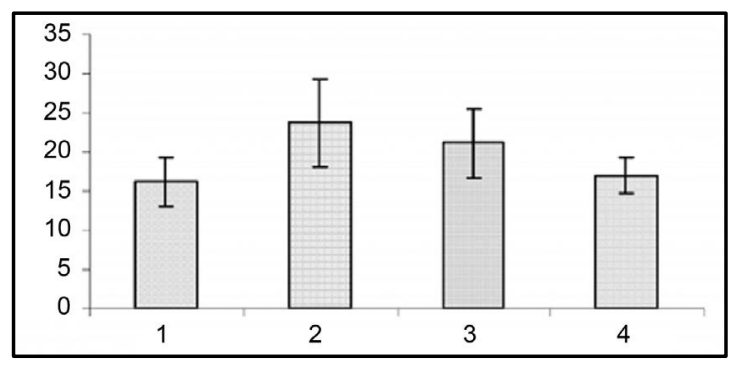

(a)

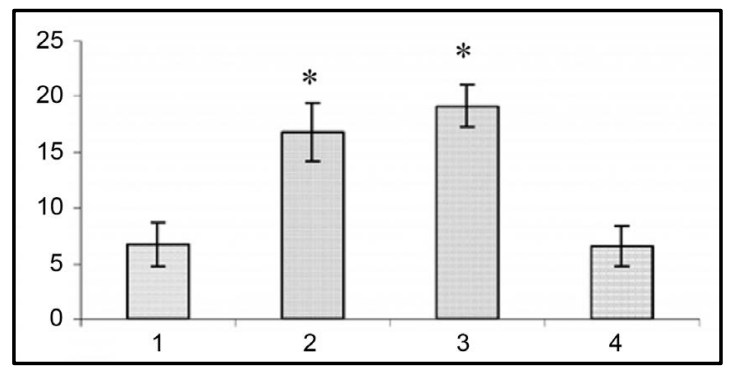

(c)

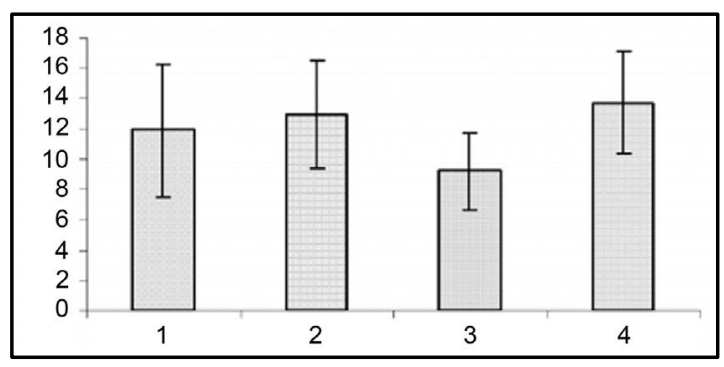

(b)

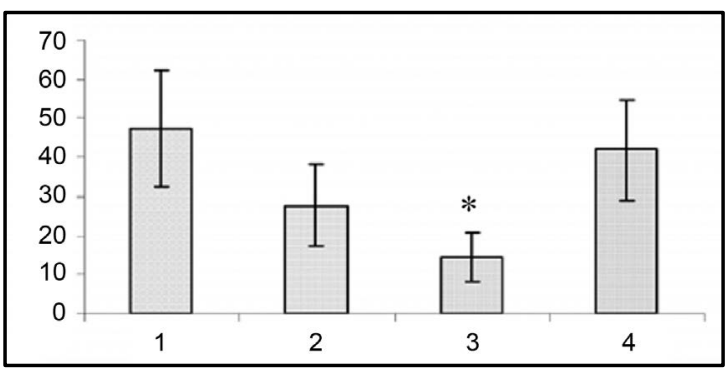

(d)

Figure 2. Changes in wild run latencies (a), wild run duration (b), pause duration between wild runs (c) and in behavioral seizure reations (d) in response to sound stimulus prior to gestation (1), at the end of gestation 2nd week (2), at the end of gestation 3rd week (3) and at the end of postgeastation 2nd week. Ordinate: time in sec. ${ }^{*} p<0.05$ compared to the seizure activity in pregestation period.

The fact of special interest is that at the 2nd and 3rd gestation week there was significant prolongation of wild run pause. After reiterative application of strong sound stimuli, not only the brain stem structures, but other brain areas (hippocampus, subcortical structures, neocortex) are involved in seizure activity, as the result the so-called audiogenic kindling develops [22]. We studied the effect of gestation on the development and course of audiogenic kindling. In these experiments we used the subline of KM rats, in which sound stimulus evoked only fear reaction, facial myoclonus, occasionally ( 3 - $8 \mathrm{sec}$ ) wild run with no behavioral clonic-tonic seizures. Figure 3 shows that control animals, which received sound stimulation in 5 - 8 days, developed behavioral clonic-tonic seizures. At the same time, there was an increase in behavioral manifestation of seizures. Pregnant rats were shown not to develop audiogenic kindling to sound stimulation. In such animals behavioral seizures were rare throughout the entire experiment, and there was no recruiting of seizure activity.

\subsection{The Effect of Ovariectomy on the Course of Audiogenic Seizure Activity}

In these experiments we used those audiogenic seizure determined rats (the rats of the first subline of the KM 
line), which developed only fear reaction and facial muscle clonus on sound stimulus with no behavioral clonictonic seizures. The animals developed severe clonic-tonic seizure reactions on the $12^{\text {th }}-14^{\text {th }}$ day after bilateral ovariectomy (Figure 4).

In the same ovariectomized rats, in order to induce pseudogestation state, high dose $(60 \mathrm{mg} / \mathrm{kg})$ of progesterone was injected intraperitoneally. It appeared that, in parallel with progesterone injection and development of pseudogestation, presentation of sound stimulus caused considerable impairment of behavioral clonic-tonic seizures. Moreover, animals developed only facial muscle clonus that had occurred before progesterone injection. In the same animals, following intraperitoneal injection of progesterone metabolism blocker Finasteride (50 - 60 $\mathrm{mg} / \mathrm{kg}$ ), the sound stimulus evoked behavioral tonic-clonic seizures like ones occurred after ovariectomy.

\section{Discussion}

\subsection{A Possible Mechanisms Changes in Seizure Activity Prior to and after Gestation}

Steroidal hormones are likely to be involved in the mechanisms, which impair the development of seizure activity. In line with the reported evidence, progesterone injection to genetically derived line of rats having no progesterone receptors results in seizure suppression [23] [24]. It is known that progesterone, by a protein 5-alpha re-

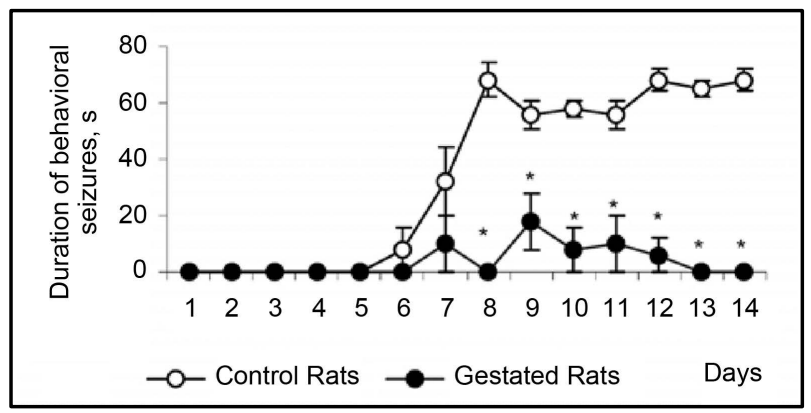

Figure 3. Development of audiogenic kindling in pregnant rats. Ordinate: behavioral seizures in sec.

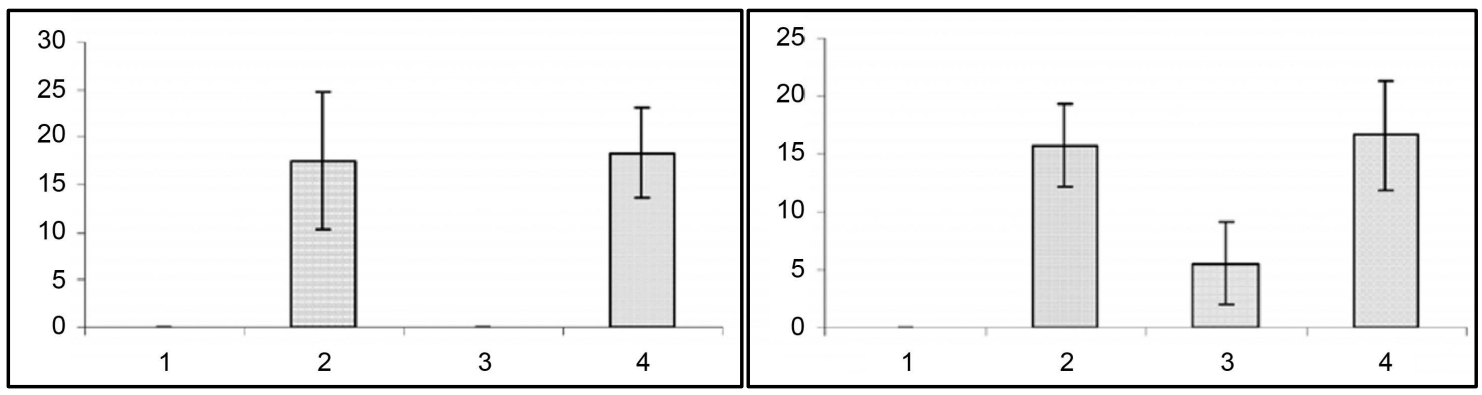

(a)

(b)

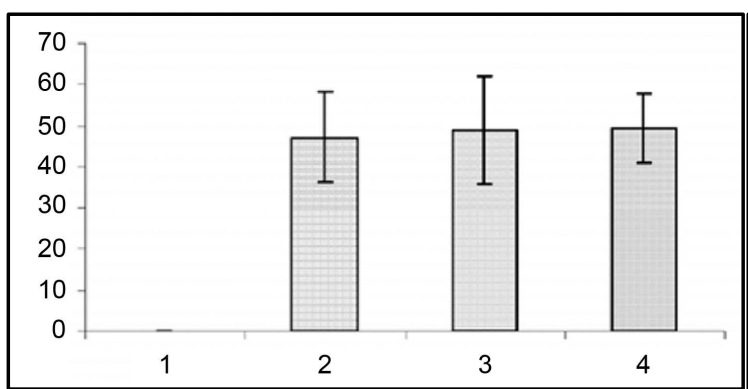

(c)

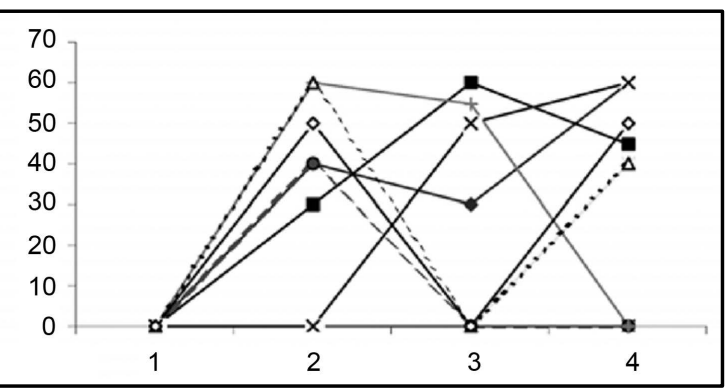

(d)

Figure 4. In response to audiogenic stimuli, changes in wild ran latencies (a), wild run duration (b), in behavioral seizures: summarized (c) and each single animal's (d) data prior to ovariectomy (1), following ovariectomy (2), after injection of progesterone (3) and of Finasteride (4). Ordinate: time in sec. 
ductase way, is converted into allopregnanolone and dioxycorticosterone derivatives [25] [26]. These neurosteroids are assumed to affect seizure activity. Presumably, there must be changes in GABAergic transmission [13] [25] [27]. On the background of progesterone administration, intraperitoneal injection of finasteride intensified behavioral seizure manifestations. Finasteride, as 5-alpha reductase inhibitor, reduces progesterone metabolism. As a result, the progesterone available in blood plasma cannot be converted into allopregnanolone, which possesses anxiolitic, anti-epileptic and sedative-hypnotic properties. Subsequently, because of little amounts of allopregnanolone, GABAergic receptors cannot be activated and this results in intensification of seizure reactions. In light of our findings it is assumed that progesterone has a distinct anticonvulsive effect. In gestation period, elevation of progesterone concentration seems to impair the process of seizure generalization.

\subsection{Changes in Behavioral Reactions to the Audiogenic Stimulation}

In spite of the fact that the wild run, which is an integral component of subsequent audiogenic behavioral seizure development [6] [15], nothing is known about the importance of the pause between the wild run and its alteration at different functional states of the brain.

Then questions arise: 1) Is the pause between wild runs triggered by the endogenous mechanisms, which impair seizure development? 2) How does gestation affect the course of pause development between wild runs?

Our experiments showed that at the 2nd and the 3rd week of gestation there was an substantial increase in the latency of the first wild run developed as a response to sound stimulation. This already suggests that the reduction of excitability in neurons of the structures involved in audiogenically induced seizures occurs during gestation. Moreover, in pregnant rats the duration of the pause between the first and the second wild runs substantially changed. Thus, it can be assumed that the pause between wild runs, in general, and during gestation, in parcitular, seems to be a manifestation of the endogenous mechanisms, which suppress seizure development.

\subsection{A Possibility of Other Neuromodulatory Systems Involvement in Changes of Seizure Activity}

Triggering of different neuromodulatory systems by gestation cannot be excluded. The importance of substantia nigra in the development of seizure activity has been shown [15] [28] [29]. In particular, damage to this substance caused intensification of seizure reactions [28]. Modulation of neuronal activity of colliculi must be due to the activation of neostriatum neurons via neurons of substantia nigra, where dopamine activity intensifies the release of GABA to the direction of substantia nigra/colliculi [15] [30]. The role of noradrenaline and serotonin in blocking of the audiogenic seizures was also suggested. Injection of serotonin precursor caused attenuation of seizure reactions [15]. By in vitro studies showed the importance of locus coeruleus in suppression of audiogenic seizure. The deficit of noradrenaline-containing fibers was shown to augment seizure activity [30].

Our experimental findings lead to a conclusion that steroidal hormones must be considered as the substances, which can, at least partially, substitute anti-epileptic drugs. This may be of greater importance to the epileptic patients, which develop tolerance to the anti-epileptic drugs.

\section{Conclusion}

The data obtained in this study showed that 1) there is a reduction of both EEG and behavioral seizures during gestation in the presence of hippocampal epileptogenic locus (kindling model); 2) suppression of audiogenic seizures and the development of audiogenic kindling occurs in gestation; 3) substantial augmentation of seizures follows bilateral ovariectomy; 4) suppression of seizures occurs in the state of pseudogestation; 5) it is assumed that, in the gestation period the intensification of the endogenous inhibitory mechanisms should follow the course of seizure activity.

\section{References}

[1] Clark, J. and Mani, S. (1994) Action of Ovarian Steroid Hormones, In: Knobil, E. and Neil, J., Eds. The Physiology of Reproduction, Vol. 1, Raven Press, New York, 1014-1059.

[2] Rogawski, M. (2003) Progesterone, Neurosteroids and the Hormonal Basis of Catamenial Epilepsy. Annals of Neurology, 53, 288-291. http://dx.doi.org/10.1002/ana.10534

[3] Veliskova, J. (2006) The Role of Estrogens in Seizures and Epilepsy: The Bad Guys or the Good Guys? Neuroscience, 
138, 837-844. http://dx.doi.org/10.1016/j.neuroscience.2005.07.005

[4] Rozciszewska, D., Buntner, I., Guz, B. and Zawisza, L. (1986) Ovarian Hormones, Anticonvulsant Drugs and Seizures during the Menstrual Cycle in the Women with Epilepsy. Journal of Neurology, Neurosurgery, Psychiatry, 49, 47-51. http://dx.doi.org/10.1136/jnnp.49.1.47

[5] Gjerde, L.O., Standjord, R.E. and Ustein, M. (1988) The Course of Epilepsy during Pregnansy: A Study of 78 Cases. Acte Neurologica Scandinavica, 78, 198-205. http://dx.doi.org/10.1111/j.1600-0404.1988.tb03646.x

[6] Gowers, W.R. (1885) Epilepsy and Other Chronic Convulsive Diseases. Their Causes, Simptoms and Treatment. William Wood, 255.

[7] Backstrom, T., Gee, K.W., Lan, N., Sorense, M. and Wahlstrom, G. (1990) Steroids in Relation to Epilepsy and Anesthesia. In: Simmonds, M.A., Ed., Steroids and Neuronal Activity, Wiley, Chichester, 224-239.

[8] Logothetis, J., Harner, R., Morell, F. and Torres, F. (1959) The Role of Estrogen in Catamenial Exacerbation of Epilepsy. Neurology, 9, 352-360.

[9] Longo, L.P. and Saldana, L.E. (1966) Hormones and Their Influence in Epilepsy. Acta Neurologica Latinoamericana, 12, 29-47.

[10] Edwards, H.E., McIntyre-Burnham, W., Mendoca, A., Bowlby, D.A. and MacLusky, N.J. (1999) Steroid Hormones Affect Limbic Afterdischarge Thresholds and Kindling Rates in Adult Female Rats. Brain Research, 16, 136-150. http://dx.doi.org/10.1016/S0006-8993(99)01619-4

[11] Veliskova, J., Velisek, L., Galanopoulou, A.S. and Sperber, E.F. (2000) Neuroprotective Effects of Estrogens on Hippocampal Cells in Adult Female Rats after Status Epilepticus. Epilepsia, 41, S30-S35. http://dx.doi.org/10.1111/j.1528-1157.2000.tb01553.x

[12] Pesce, M.E., Acevedo, X., Bustamante, D., Miranda, H.F. and Pinardi, G. (2000) Progesterone and Testosterone Modulate the Convulsant Actions of Pentylenetetrazol and Strychnine in Mice. The Pharmacology and Toxicology, 87, 116-119.

[13] Velisek, L. and Veliskova, J. (2001) Estrogen Treatment Protects GABA-b Inhibition in the Dentate Gyrus of Female Acid-Induced Status Epilepticus. Epilepsia, 43, 146-151. http://dx.doi.org/10.1046/j.1528-1157.43.s.5.3.x

[14] Goddard, G.V., McIntyre, C. and Leech, C.K. (1969) A Permanent Change in Brain Function Resulting from Daily Electrical Stimulation. Experimental Neurology, 25, 295-330. http://dx.doi.org/10.1016/0014-4886(69)90128-9

[15] Ross, K.C. and Coleman, J.R. (2000) Developmental and Genetic Audiogenic Seizure Models: Behavior and Biological Substrats. Neuroscience and Biobehavioral Reviews, 24, 639-653. http://dx.doi.org/10.1016/S0149-7634(00)00029-4

[16] Browing, R.A., Wang, C., Nelson, D.K. and Jobe, P.C. (1999) Effect of Precollicular Transection on Audiogenic Seizures in Genetically Epilepsy-Prone Rats. Experimental Neurology, 155, 295-301. http://dx.doi.org/10.1006/exnr.1998.6981

[17] (1986) Guide for the Care and Use of Laboratory Animals. US Department of Health and Human Services.

[18] Krushinsky, L.V., Molodkina, L.N., Fless, D.A., Dobrokhotova, L.P., Steshenko, A.P., Semiokhina, A.F., Zorina, Z.A. and Romanova, L.G. (1970) The Functional State of the Brain during Sonic Stimulation. In: Welch, B.L. and Welch, A.S., Eds., Physiological Effects of Noise, Plenum Press, New York, 151-158. http://dx.doi.org/10.1007/978-1-4684-8807-4_15

[19] Mondes, M. and Radke, R.A. (2001) Interactions between Sleep and Epilepsy. Journal of Clinical Neurophysiology, 18, 106-127. http://dx.doi.org/10.1097/00004691-200103000-00003

[20] Racine, R. (1972) Modification of Seizure Activity by Electrical Stimuletion: II. Motor Seizure. Electroencephalography and Clinical Neurophysiology, 32, 281-294. http://dx.doi.org/10.1016/0013-4694(72)90177-0

[21] Jobe, P.C., Picchioni, A.L. and Lhin, L. (1973) Role of Norepinephrine in Audiogenic Seizure in the Rat. Journal of Pharmacology end Experimental Therapy, 184, 1-10.

[22] Naritoku, D.K., Mecozzi, L.B., Aiello, M.T. and Faingold, C.L. (1992) Repetition of Audiogenic Seizures in Genetically Epilepsy-Prone Rats Induced Cortical Epileptiform Activity and Additional Seizure Behavior. Experimental Neurology, 115, 317-324. http://dx.doi.org/10.1016/0014-4886(92)90197-X

[23] Mihalek, R. (1999) Attenuated Sensitivity Neuroactive Steroids in $g$-Aminobutyrate Type-A Receptor $g$-Subunit Knockout Mice. Proceedings of the National Academy of Sciences of the United States of America, 96, 12905-12910.

[24] Micevich, P., Kiran, K. and Sinchak, K. (2008) Neuroprogesterone: Key to Estrogen Feedback? Brain Research Reviews, 57, 470-480. http://dx.doi.org/10.1016/j.brainresrev.2007.06.009

[25] Zeng, P. (2009) Neuroactive Steroid Regulation of Neurotransmitter Release in the CNS: Action, Mechanism and Possible Significance. Progress in Neurobiology, 89, 134-152. http://dx.doi.org/10.1016/j.pneurobio.2009.07.001 
[26] Frye, C.A. and Bayon, L.E. (1998) Seizure Activity Is Increased in Endocrine States Characterized by Decline in Endogenous Levels of the Neurosteroid $3 \alpha, 5 \alpha$-THP. Neuroendocrinology, 68, 272-280. http://dx.doi.org/10.1159/000054375

[27] Wang, J.M., Liu, L., Ronald, W., Chen, S. and Brinton, R.D. (2008) Regenerative Potential of Allopregnanolone. Brain Research Reviews, 57, 398-409. http://dx.doi.org/10.1016/j.brainresrev.2007.08.010

[28] Dorreto, M.C. and Garcia-Cairasco, N. (1995) Differential Audiogenic Seizure Sensitization by Selective Unilateral Substantia Nigra Lesions in Resistant Wistar Rats. Physiology and Behavior, 58, 273-282. http://dx.doi.org/10.1016/0031-9384(95)00050-S

[29] Browing, R.A., Lanker, M.L. and Faingold, C.L. (1989) Injections of Noradrenergic and GABAergic Agonists into the Inferior Colliculus: Effects on Audiogenic Seizures in Genetically Epilepsy-Prone Rats. Epilepsy Research, 4, 119-125. http://dx.doi.org/10.1016/0920-1211(89)90016-8

[30] Clough, R.W., Peterson, B.R., Steenbergen, J.L., Jobe, P.C., Eells, J.B., Browning, R.A. and Mishra, P.K. (1998) Neurite Extension of Developing Noradrenergic Neurons Is Impaired in Genetically Epilepsy-Prone Rats(GEPR-3s): An in Vitro Study on the Locus Coeruleus. Epilepsy Research, 29, 135-146.

http://dx.doi.org/10.1016/S0920-1211(97)00076-4 
Scientific Research Publishing (SCIRP) is one of the largest Open Access journal publishers. It is currently publishing more than 200 open access, online, peer-reviewed journals covering a wide range of academic disciplines. SCIRP serves the worldwide academic communities and contributes to the progress and application of science with its publication.

Other selected journals from SCIRP are listed as below. Submit your manuscript to us via either submit@scirp.org or Online Submission Portal.
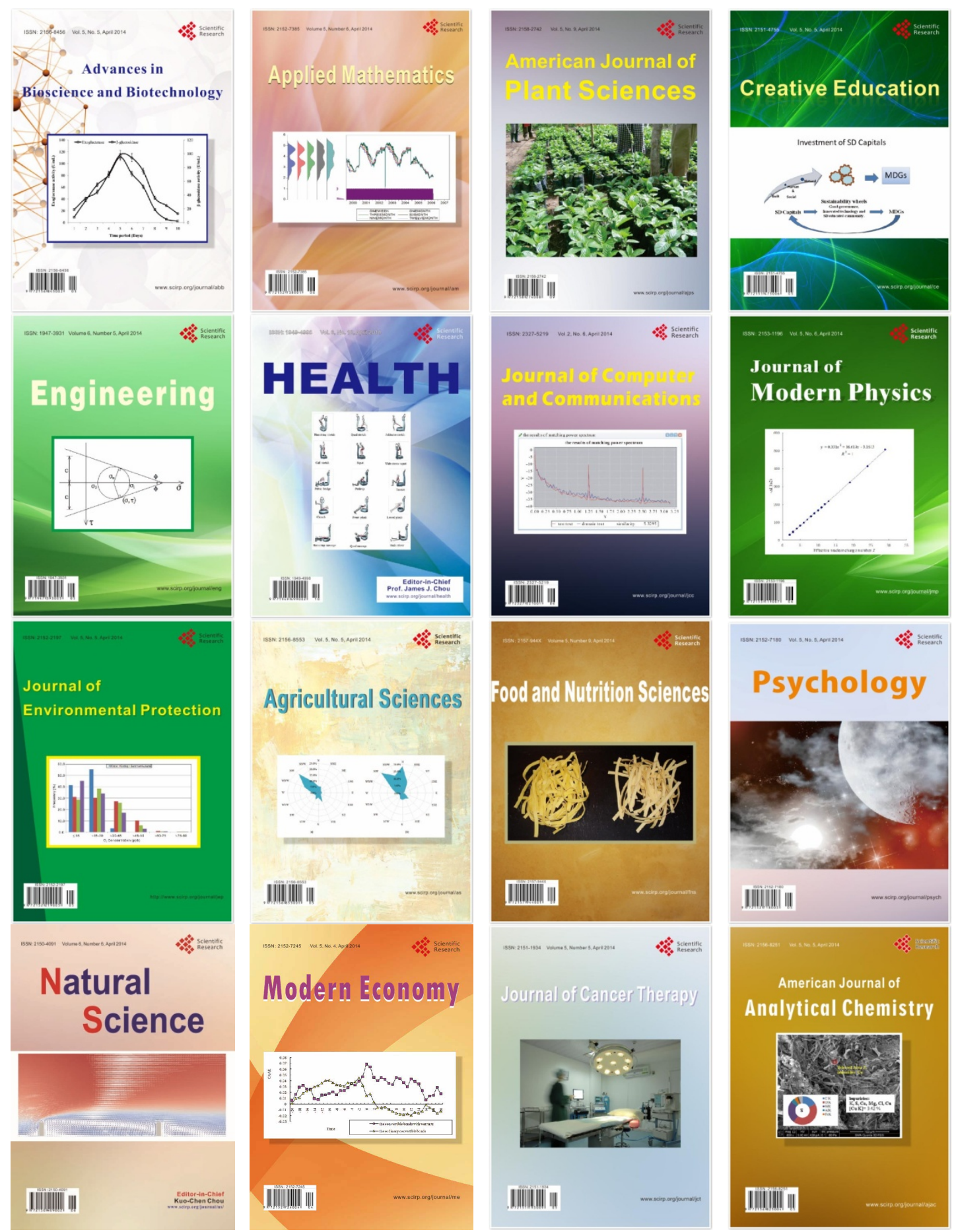